\title{
Synthesis, Characterization, and Evaluation of Radical Scavenging Ability of Ellagic Acid-Loaded Nanogels
}

\author{
Gautam Behl, ${ }^{1}$ Monal Sharma, ${ }^{2}$ Saurabh Dahiya, ${ }^{3}$ Aruna Chhikara, ${ }^{1}$ and Madhu Chopra ${ }^{2}$ \\ ${ }^{1}$ Department of Chemistry, Dyal Singh College, University of Delhi, Lodhi Road, New Delhi 110003, India \\ ${ }^{2}$ Dr. B. R. Ambedkar Center for Biomedical Research, University of Delhi, New Delhi 110007, India \\ ${ }^{3}$ Department of Anatomical Sciences and Neurobiology, University of Louisville School of Medicine, Louisville, KY 40292, USA
}

Correspondence should be addressed to Aruna Chhikara, arunachhikara@gmail.com and Madhu Chopra, mchopradu@gmail.com

Received 14 May 2011; Accepted 12 August 2011

Academic Editor: Daxiang Cui

Copyright () 2011 Gautam Behl et al. This is an open access article distributed under the Creative Commons Attribution License, which permits unrestricted use, distribution, and reproduction in any medium, provided the original work is properly cited.

Ellagic acid (EA), a potential antioxidant phytochemical has low aqueous solubility and bioavailability. In this paper, encapsulation of ellagic acid has been carried out into the biodegradable disulfide crosslinked poly (ethylene glycol) PEO-based nanogels synthesized via AGET (activator generated electron transfer) ATRP (atom transfer radical polymerization), and their radical scavenging ability was evaluated. The encapsulation of the EA was carried out at two drug loading percentages, that is, 10 and $20 \mathrm{wt}$.\% of the nanogels. 1,1-Diphenyl-2-picryldrazyl (DPPH) assay was utilized in order to assess the radical scavenging ability of the ellagic acid-loaded nanogels. A drug-loading level of about $2.5 \mathrm{wt} . \%$ was achieved with encapsulation efficiency of about $25 \%$ at 10 wt. $\%$ of the EA w.r.t nanogels, which was found to increase to about 4.7 wt.\% with decreased encapsulation efficiency of $23.5 \%$ as EA content was increased to $20 \mathrm{wt} . \%$ of the nanogels. Ellagic acid loading was found to be accompanied with increase in the size of the nanogels from $144.6 \pm 39.52 \mathrm{~nm}$ for neat nanogels to $217.8 \pm 105.5$ and $633 \pm 160.1 \mathrm{~nm}$ at 2.5 and $4.7 \mathrm{wt} . \% \mathrm{drug}$ loading level. The nanogels were found to be capable of scavenging radicals and biocompatible on human cervical cancer cell lines (HeLa cells) at appropriate concentrations.

\section{Introduction}

It is widely known that fruits and vegetables are rich in compounds which prevent cancer and are free radical scavengers. These compounds are generally phenolic acids with a single ring structure and flavonoids containing several hydroxyl groups associated with phenolic groups. Oxidative stress which is caused by an imbalance between the antioxidants and oxidants is responsible for many diseases including cancer [1]. EA, a naturally occurring polyphenolic compound, present in fruits and nuts such as blueberries, red raspberries, pomegranates, walnuts, and grape seeds, is very well known to possess antioxidant, anticarcinogenic, and antimutagenic properties [1-6]. Due to its low water solubility and permeability, EA falls under Class IV of the biopharmaceutic classification system $[7,8]$. EA is not only insoluble in water (water solubility $\simeq 9.7 \mu \mathrm{g} / \mathrm{mL}$ ) [9] but also difficult to solubilize in commonly used organic solvents which is a prerequisite for a pharmaceutical entity to be formulated into a dosage form. Animal studies suggest that orally administered EA is poorly absorbed and its retention in the body is very low and hence therapeutic effects could not be achieved $[10,11]$. The low oral bioavailability of EA can be attributed to its low aqueous solubility, metabolism in the gastrointestinal tract, irreversible binding to cellular DNA and proteins and firstpass effect $[8,12]$. Hence, there is a strong need to develop an effective delivery carrier for EA, to achieve considerable therapeutic output.

Nanoparticles are a reliable option for the delivery of poorly water soluble drugs [7]. Recently, nanoemulsionbased formulation of poorly soluble anticancer drug Paclitaxel has been prepared showing enhanced anticell prolifeative capacity and apoptotic properties [13]. The aims for nanoparticle entrapment of drugs are enhanced delivery to or uptake by target cells and/or a reduction in the toxicity of the free drug to nontarget organs. For these aims, synthesis of 
long-lived nanoparticles is needed [14]. Poly(ethylene glycol) particularly solves these problems owing to its prolonged presence in the blood circulation by inhibiting recognition and phagocytosis by the mononuclear phagocytic system [15]. In recent years, ATRP (atom transfer radical polymerization) has emerged as a very useful technique for the synthesis of biodegradable and biocompatible polymers for the delivery of therapeutic agents [16-20]. The technique has been known to be very useful for the synthesis of colloidal particles with halide end functionality which may be advantageous for further chain extension, formation of block copolymers and conjugation with bio-related molecules, resulting in the formation of polymer-biomolecule conjugates [21-24].

In this paper we report a simple method for the encapsulation of EA into the poly(ethylene glycol)-based disulfide crosslinked nanogels, by simply suspending them into a solution of EA in methanol with PEG-400 as cosolvent. The method is simple and does not require use of any stabilizer or surfactant and any complexation strategy used earlier [2, 7, $8]$. The nanogels were synthesized via AGET ATRP in an inverse miniemulsion, which is a known technique for controlled polymerization with prepared polymer chains having polydispersity index $(\mathrm{PDI}) \approx 1[17,18,25]$. The nanogels were synthesized by using poly(ethylene glycol) which is itself a biocompatible material and known to enhance the circulation lifetime in the blood and prevent opsonization of the particles $[26,27]$ ensuring that carrier will be retained in the body for the maximum possible time, in order to achieve enhanced therapeutic output. The disulfide crosslinker used here further adds biodegradability to the nanogels and is known to degrade in the presence of tripeptide glutathione present within the cells [17].

\section{Materials and Methods}

2.1. Materials. Ellagic acid was obtained from Sigma Aldrich. Poly(ethylene glycol) monomethylether with $M_{n}=5000$ (PEO5000-OH) was used as received from Fluka. Poly (ethylene glycol) monomethacrylate (PEOMA526, $M_{n}=$ $526 \mathrm{~g} / \mathrm{mol}$ ) was purchased from Sigma-Aldrich and purified according to the procedure reported earlier [25]. Copper (II) bromide $\left(\mathrm{CuBr}_{2}, 99 \%\right), 1,3$-dicyclohexylcarbodiimide (DCC, 99\%) were used as received from Acros. Oligo (ethylene glycol) monomethyl ether methacrylate (OEOMA) molecular weight $M=300 \mathrm{~g} / \mathrm{mol}$, pendent EO units DP $\approx 5$, was purchased from Aldrich and purified by passing it through a column filled with basic alumina to remove the inhibitor. 2-Bromo-2-methyl propionyl poly (ethylene glycol) monomethyl ether (PEO5000-Br) macroinitiator, dithiopropionyl poly (ethylene glycol) dimethacrylate (DMA) crosslinker, and tris [(2-pyridyl) methyl] amine (TPMA) ligand were synthesized according to the procedure reported earlier $[16,17,28]$. 2-Bromo-2-methylpropionic acid (98\%), 4-dimethyl aminopyridine (DMAP, 99+\%), 3, 3 '-dithiopropionic acid, glutathione ethyl ester (reduced form), L-ascorbic acid (99+\%), sorbitan monooleate (Span 80), cyclohexane (HPLC grade), MTT (3-(4,5-dimethyl-2yl)-2,5-diphenyltetrazolium bromide), and DPPH were used as received from Aldrich. All other chemicals and reagents used were of analytical grade.

\subsection{Methods}

2.2.1. Characterization Methods. TEM micrographs were obtained on TECNAI G ${ }^{2}-30$ U-TWIN FEI Company HR-TEM at $200 \mathrm{KV}$ (University Science Instrumentation Center Facility, University of Delhi). Size distribution characterization of the nanogels was carried out on DLS (dynamic light scattering) by dispersing nanogels in cyclohexane using DLS; FAST Version 2.8.3.Alango Ltd (Lab facility of Prof. Subho Mozumdar, Dept. of Chemistry, University of Delhi). FTIR (Fourier fransform infrared) spectra of the nanogels were recorded using Perkin Elmer Spectrum BX Series instrument by the $\mathrm{KBr}$ disc method. ${ }^{1} \mathrm{H}$ NMR spectra were recorded on Bruker Avance II $400 \mathrm{MHz}$ instrument (NMR facility, Institute of Nuclear Medicine \& Allied Sciences, Defence Research and Development Organisation, New Delhi). EPR (electron paramagnetic resonance) spectra were recorded on JES-FA ESR spectrometer with settings: magnetic field, $336.5 \pm 5 \mathrm{mT}$; power, $2 \mathrm{~mW}$; modulation frequency, $9.435 \mathrm{GHz}$; amplitude, $1 \times 1000$; modulation width, $0.8 \mathrm{mT}$; sweep width, $10 \mathrm{mT}$; sweep time, 30 s. (JEOL LTD.) (University Science Instrumentation Center Facility, University of Delhi). UVvisible study was carried out on Perkin Elmer Lambda 25 spectrophotomer at ACBR.

2.2.2. Synthesis of (P (OEOMA)) Nanogels by AGET ATRP. Poly(oligoethylene glycol) monomethacrylate (P (OEOMA)) nanogels were synthesized by carrying out an AGET ATRP reaction in an inverse miniemulsion according to the procedure described earlier (Figure 1) [16, 17]. Briefly, OEOMA 300 (1.4 g, $4.67 \mathrm{mmol})$, PEO5000-Br (79.8 mg, $0.016 \mathrm{mmol})$, TPMA (2.3 mg, $0.008 \mathrm{mmol}), \mathrm{CuBr}_{2}(1.7 \mathrm{mg}, 0.008 \mathrm{mmol})$, and water $(1.4 \mathrm{~mL})$ were mixed in a $50 \mathrm{~mL}$ round bottom flask at room temperature, and $1.5 \mathrm{~mol} \%$ DMA in aqueous solution was introduced. The resulting clear solution was then mixed with a solution of Span 80 (surfactant) $(1.0 \mathrm{~g})$ in cyclohexane $(20 \mathrm{~g})$, and the mixture was sonicated for $2 \mathrm{~min}$ in an ice bath at $0^{\circ} \mathrm{C}$ to form a stable inverse miniemulsion. The dispersion was transferred into a $50 \mathrm{~mL}$ Schlenk flask and then bubbled with nitrogen for $30 \mathrm{~min}$. The flask was immersed in water bath preheated to $30^{\circ} \mathrm{C}$, and then an argon-purged aqueous solution of ascorbic acid $(0.005 \mathrm{mmol}, 192 \mu \mathrm{L})$ was added via syringe to start polymerization. The polymerization was stopped after $2 \mathrm{~h}$ by exposing the reaction mixture to air. The resulting nanogel was purified by removal of the cyclohexane followed by addition of THF and the resulting heterogeneous mixture was stirred at room temperature for $5 \mathrm{~h}$. The gels were separated by centrifugation $(15,000 \mathrm{rpm} \times 20 \mathrm{~min})$ and decantation of the supernatant. THF was added and the same procedure was repeated twice. After the final wash, the precipitate was dried in a vacuum oven at $30^{\circ} \mathrm{C}$ for $2 \mathrm{~h}$ to yield the nanogels.

2.2.3. Degradation Study of the Nanogels in Presence of Glutathione. A degradation study of nanogels was performed in 
<smiles>COCCOC(=O)C(C)=[C-]COCCOC(=O)C(C)(C)Br</smiles><smiles>N#CCOc1cccc(CN(Cc2ccccn2)Cc2ccccn2)n1</smiles>

Disulfide crosslinked P(OEOMA) nanogels

FIGURE 1: Schematic representation of the syntheses of $\mathrm{P}(\mathrm{OEOMA})$ nanogels via inverse miniemulsion ATRP.

the presence of glutathione according to the procedure reported earlier [17] with slight modification. Briefly, $20 \mathrm{mg}$ of the nanogels were fully swollen in water $(1.7 \mathrm{~mL})$ for 3 days and then centrifuged to separate the gels (W1). The nanogels were then mixed with $10 \mathrm{wt} . \%(2 \mathrm{mg})$ and $20 \mathrm{wt} . \%$ of the glutathione in water $(1.7 \mathrm{~mL})$ and allowed to stir at room temperature for appropriate time and centrifuged $(15000 \mathrm{rpm} \times 20 \mathrm{~min})$ to separate the gels (W2). The extent of degradation was calculated from the equation in terms of weight fraction $(\mathrm{W} 2 / \mathrm{W} 1 \times 100)$ of the nanogels remained. A control experiment was also carried out using similar conditions in the absence of glutathione.

2.2.4. Drug Loading. Required amount of nanogels was allowed to stir in methanol: poly(ethylene glycol) $\left(M_{n}=400\right)$ solution $(2400: 600 \mu \mathrm{L}$ for every $1 \mathrm{mg}$ of EA) for 5 days. At the end of this period, the contents were centrifuged to precipitate nanogels, which were washed repeatedly with methanol and dried in vacuum. The amount of drug loading was calculated indirectly by taking absorbance of the supernatant at $361 \mathrm{~nm}$, and fitting the absorbance value in Beer-Lambert equation with predetermined extinction coefficient of EA.

2.2.5. DPPH Radical Scavenging Ability of the EA-Loaded Nanogels. DPPH radical scavenging activity of the EA-loaded nanogels was determined by UV-visible spectrophotometric method and EPR spectroscopy according to the procedure reported earlier $[29,30]$ at predetermined concentrations with slight modifications. The results were expressed in terms of absorbance decay of DPPH at $517 \mathrm{~nm}$ and decrease in the height of EPR signal. About $100 \mu \mathrm{L}$ of the suspension of EA-loaded nanogels in water was mixed with $900 \mu \mathrm{L}$ of the DPPH $(100 \mu \mathrm{M})$ in ethanol solution. The solution was mixed and incubated for $30 \mathrm{~min}$ at room temperature in dark. The absorbance of the final solution was recorded spectrophotometrically at a wavelength of $517 \mathrm{~nm}$. For EPR study about $50 \mu \mathrm{L}$ of the suspension of the drug-loaded nanogels was added to $150 \mu \mathrm{L}$ of the ethanolic solution of DPPH $(100 \mu \mathrm{M})$. After mixing vigorously for $10 \mathrm{~s}$, the solution was transferred into a quartz capillary tube and its radical scavenging activity was measured in terms of peak height.

2.2.6. In Vitro Cytotoxicity of the EA-Loaded Nanogels. Cytotoxicity of the EA-loaded nanogels was determined by MTT assay as described elsewhere [31]. Briefly, the cells were grown in 96-well plates at a density of $5 \times 10^{4}$ cells/well. After $24 \mathrm{~h}$, cells were washed with fresh medium and treated with neat and EA-loaded nanogels at varying concentrations. After $48 \mathrm{~h}$ of incubation, cells were rewashed and $50 \mu \mathrm{L}$ of MTT $(5 \mathrm{mg} / \mathrm{mL})$ was added to each well and incubated for $4 \mathrm{~h}$. Finally, $200 \mu \mathrm{L}$ of DMSO was added to solubilize 


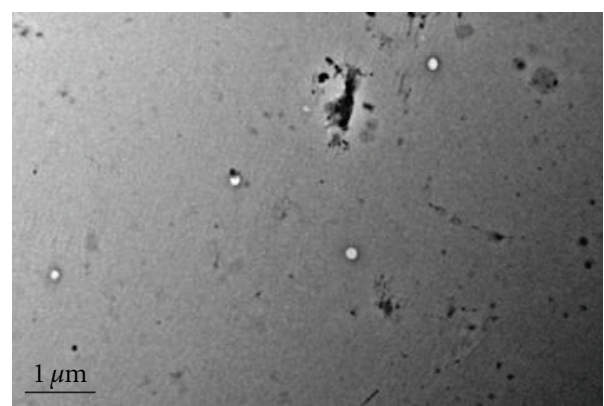

(a)

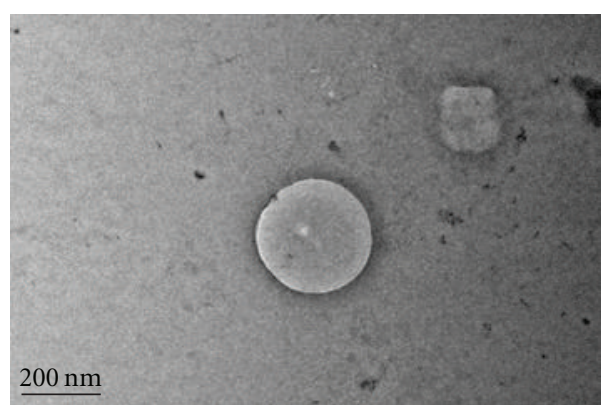

(b)

FIGURE 2: HR-TEM micrographs of the nanogels at $1 \mu \mathrm{m}$ (a) and $200 \mathrm{~nm}$ (b) scale bar. Nanogels were suspended in water by sonication and then mounted on a carbon-coated TEM grid.

the formazan salt formed and the amount of formazan salt was determined by measuring the optical density (OD) at $540 \mathrm{~nm}$ using a GENios microplate reader (TECAN Austria $\mathrm{GmbH}$, Grodig/Salzburg, Austria).

\section{Results and Discussion}

ATRP in an inverse miniemulsion enables the formation of uniformly crosslinked particles and gels with well-controlled polymer segments $[16,32-34]$. This approach has become very useful for the preparation of biomaterials with many predeterminable site specific features, including uniform network, high loading efficiency of biomolecules or drugs, distributed halide end-group functionalities, and degradable interior [16]. Based on this method we synthesized $\mathrm{P}$ (OEOMA) nanogels in inverse miniemulsion, and their spherical morphology was revealed by TEM micrographs as shown in Figure 2.

The nanogels were insoluble in a number of solvents including THF and water, but when incubated with appropriate concentrations of glutathione they got degraded and became soluble in water. The extent of degradation was found to be dependent on the concentration of the glutathione as evident from Figure 3.

There was no degradation in the control setup, however, $78 \%$ of the nanogels degraded in the presence of $20 \mathrm{wt} . \%$ glutathione, comparable to the previously reported results [17]. Authors in this paper synthesized the nanogels via ATRP, a degradation study was carried out in the presence of tripeptide glutathione resulting in reduction of the disulfide group to the corresponding thiols making the water soluble byproducts. Our approach was based on the use of these disulfide crosslinked nanogels as biodegradable carriers, as these groups add biodegradability to the nanogels $[32,35]$ in the presence of glutathione within the cells [36]. The results obtained here confirm that the nanogels were crosslinked with disulfide crosslinker and their excretion from the body would be easier after their degradation in the presence of glutathione.

A wide variety of drugs can be delivered using nanoparticulate carriers via a number of routes. Size of the nanoparticles is very crucial for their uptake via any route. For oral

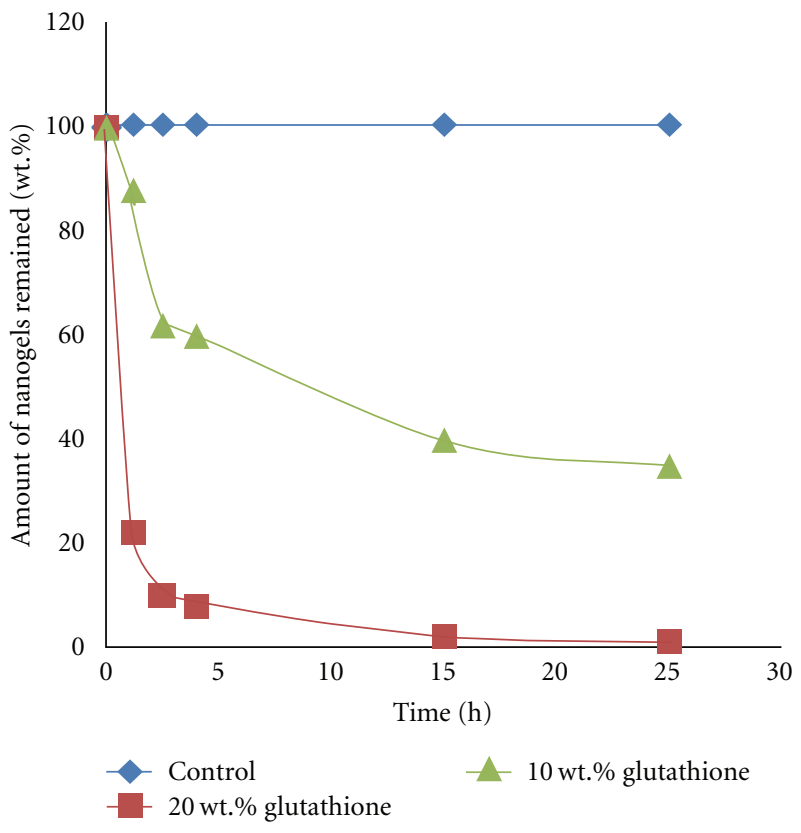

FIGURE 3: Degradation of the nanogels in terms of weight fraction of the nanogels remained in the presence of different concentrations of glutathione with time.

TABLE 1: DLS data of the nanogels dispersed in cyclohexane at $30^{\circ} \mathrm{C}$.

\begin{tabular}{lcc}
\hline & $\begin{array}{c}\text { Drug-loaded } \\
\text { nanogels (wt \%) }\end{array}$ & $\mathrm{D}_{\mathrm{av}}{ }^{*}(\mathrm{~nm})$ \\
\hline Neat nanogels & - & $144.6 \pm 39.52$ \\
& 2.5 & $217.8 \pm 105.5$ \\
& 4.7 & $633 \pm 160.1$ \\
\hline
\end{tabular}

${ }^{*} \mathrm{D}_{\mathrm{av}}$ is average diameter \pm standard deviation.

route where the lymphatic uptake of the nanoparticles by the Payer's patches in the GALT (gut-associated lymphoid tissue) is of major interest, the optimum size ranges from less than $1 \mu \mathrm{m}$ to $5 \mu \mathrm{m}$. Whereas for intravenous delivery it becomes smaller than $5 \mu \mathrm{m}$ [37]. Here in our case, DLS measurement of the nanogels revealed a size distribution of about $144.6 \pm$ $39.52 \mathrm{~nm}$ (Figure 4 and Table 1) within the prescribed limits comparable to the size obtained earlier $[16,17]$. 


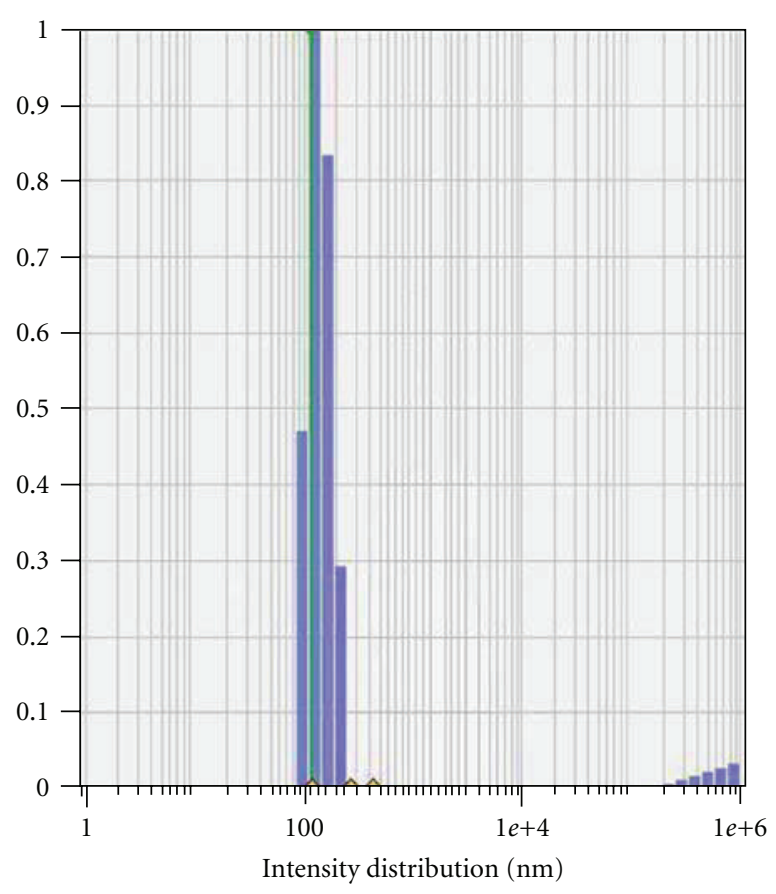

(a)

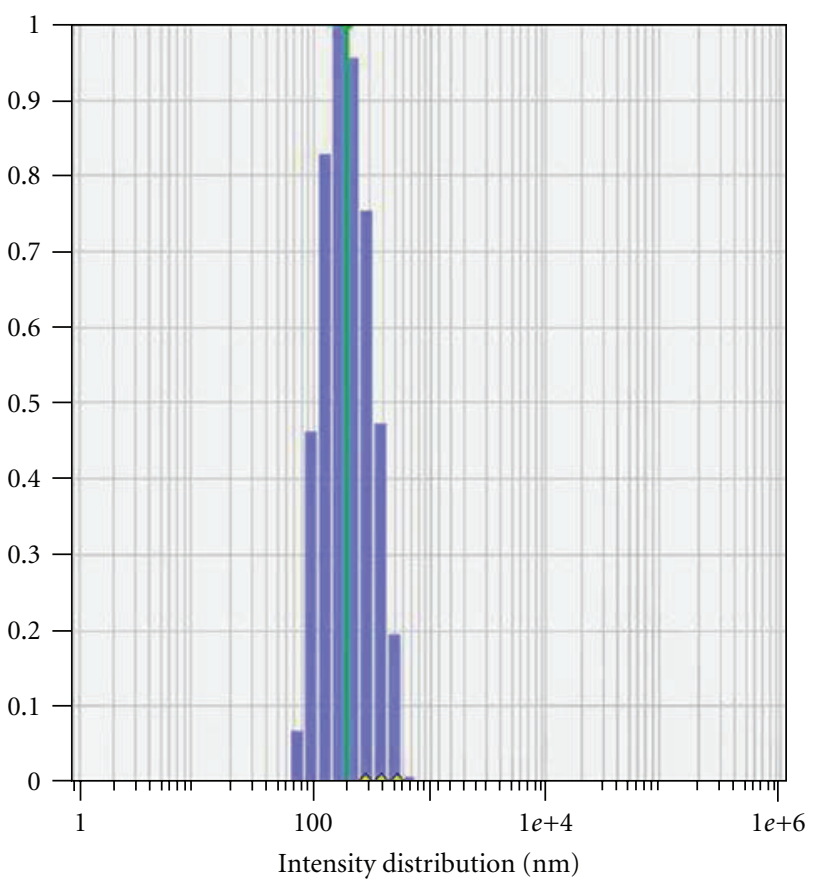

(b)

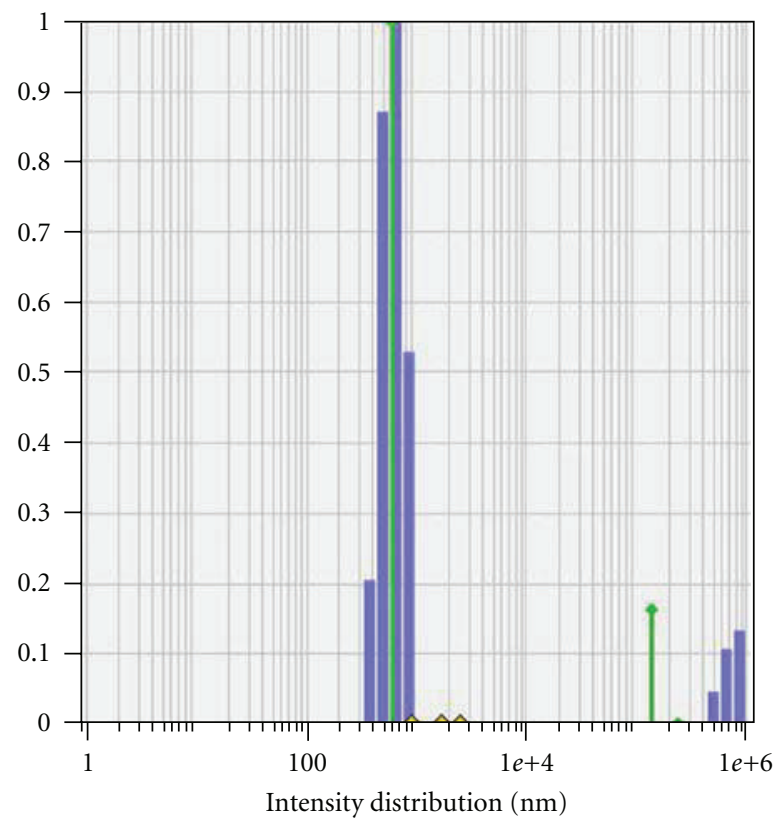

(c)

FiguRE 4: DLS measurement of the neat nanogels (a) and drug-loaded nanogels at 2.5 wt.\% (b) and 4.7 wt.\% (c) drug loading-level. Nanogels were sonicated and suspended in cyclohexane for carrying out the measurement.

Several studies have been reported where these nanogels were used as biodegradable carriers of anticancer agents. Studies were performed by encapsulation of doxorubicin [17] and rhodamine B isothiocyanate-dextran [18] as model drugs. We carried out encapsulation studies of Ellagic acid, a naturally occurring polyphenolic compound, for our work. As already stated, EA has lower solubility and permeability profile. Being a medicinally important compound, its delivery in the form of solubilised nanogels may be of interest for pharmaceutically usable dosage form. A stable solution of EA was formed in methanol with PEG-400 as cosolvent. The absorbance of characteristic peak of EA at $361 \mathrm{~nm}$ was measured as described in methods section. At about $10 \mathrm{wt} . \%$ of initial drug load, $2.5 \mathrm{wt} . \%$ drug loading was achieved 


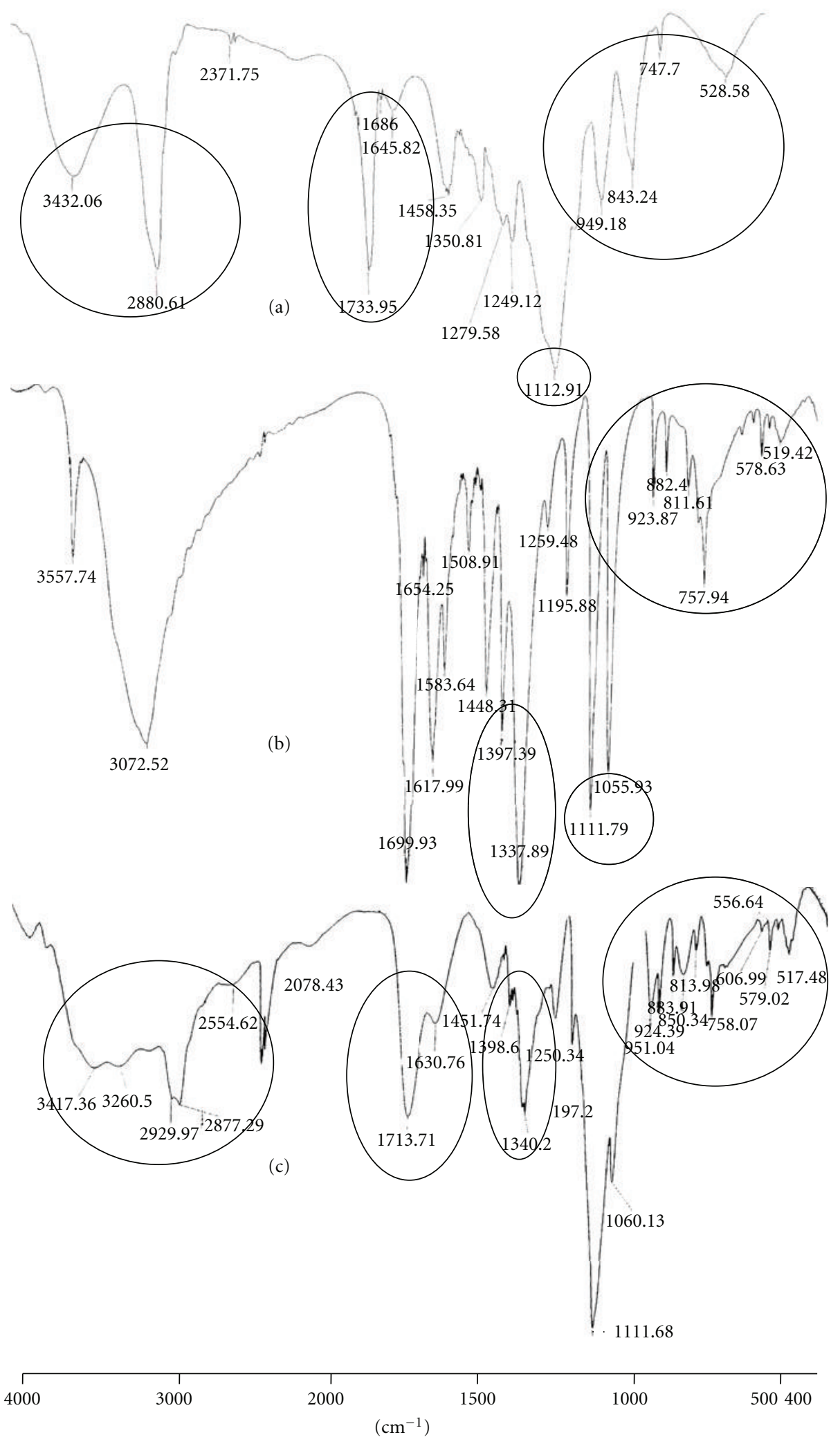

FIgURE 5: FTIR spectra of the nanogels (a), EA (b) and EA-loaded nanogels (c). 
TABle 2: Drug-loading level and encapsulation efficiency of EA into the nanogels.

\begin{tabular}{lcc}
\hline EA/nanogels (wt\%) & $\begin{array}{c}\text { Loading level } \\
(\mathrm{wt} \%)\end{array}$ & $\begin{array}{c}\text { Loading efficiency } \\
(\mathrm{wt} \%)\end{array}$ \\
\hline 10 & 2.5 & 25 \\
20 & 4.7 & 23.5 \\
\hline
\end{tabular}

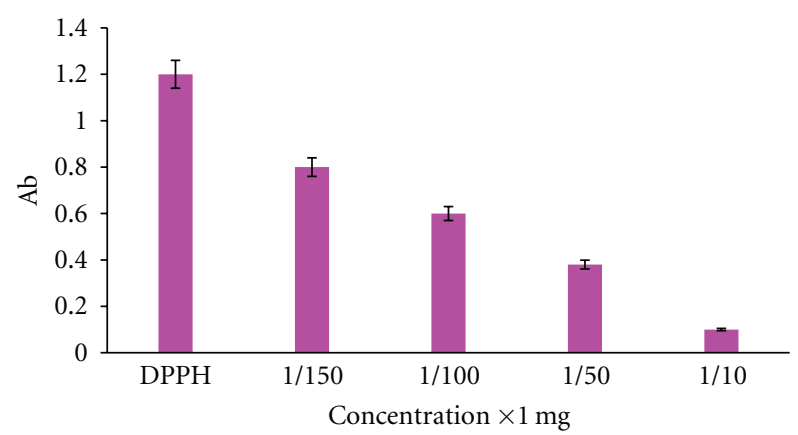

FIGURE 6: DPPH radical scavenging effect of the ellagic acid-loaded nanogels in terms of absorbance decay at $517 \mathrm{~nm}$. Results are means \pm standard error of three independent experiments.

with an encapsulation efficiency of $25 \%$. The drug loading levels increased to $4.7 \mathrm{wt} . \%$ at $20 \mathrm{wt} . \%$ drug load, however encapsulation efficiency decreased to 23.5 wt.\% (Table 2).

Our results are similar to those reported earlier $[17,18]$ where the encapsulation efficiency followed the similar trend as observed in our studies. In another previous report, authors observed decrease in encapsulation efficiency trend for EA encapsulation in a different system with nanoparticle based on poly (lactide-co-glycolide) [7] using polyvinyl alcohol and chitosan as stabilizers. Moreover, in our case we did not utilize any surfactant or stabilizer for encapsulation of EA into the nanogels, hence it may be stated that our method is advantageous to earlier reported method [7] and encapsulation efficiency achieved is comparable with other cytotoxic anticancer compounds discussed above.

Loading of the drug molecules into the nanogels affects the size. EA loading was also found to be accompanied with increase in size distribution of the nanogels (Figure 4 and Table 1). The size distributions of the nanogels were $217.8 \pm$ 105.5 and $633 \pm 160.1 \mathrm{~nm}$ at 2.5 and $4.7 \mathrm{wt} . \%$ drug-loading level. This increase in the size of nanogels can be attributed to the increased amount of EA into the nanogels similar to the results reported earlier [7].

FTIR spectroscopy has been used frequently for the characterization of the prepared formulation and any kind of interaction between drug and the matrix of the carrier $[12,38$, 39]. For an ideal drug carrier it becomes necessary that it should not have any chemical interaction that leads to any change in the chemical structure of drug. The FTIR spectra obtained for the nanogels, EA and EA-loaded nanogels are shown in Figure 5. The spectrum of the nanogels shows characteristic bands around 1733 and $1100 \mathrm{~cm}^{-1}$ which are attributed to the $\mathrm{C}=\mathrm{O}$ stretch of the ester groups and $\mathrm{C}-$ $\mathrm{O}-\mathrm{C}$ skeletal stretch of poly(ethylene glycol) backbone,

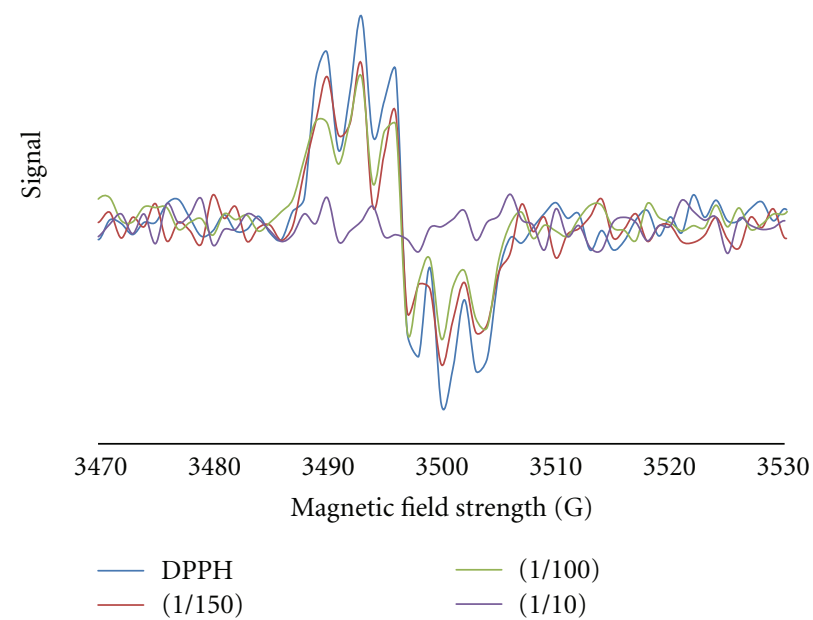

FIGURE 7: EPR spectra of the DPPH radical at indicated dilutions of the $1 \mathrm{mg}$ of $4.7 \mathrm{wt}$ \% EA-loaded nanogels.

respectively, that was also observed in the spectrum of EAloaded nanogels. A band around $1195 \mathrm{~cm}^{-1}$ was observed in the spectrum of EA and EA-loaded nanogels due to the $\mathrm{C}-\mathrm{O}$ stretch of the lactone group. The fingerprint regions of both nanogels and EA (900 to $500 \mathrm{~cm}^{-1}$ ) were observed in the spectrum of EA-loaded nanogels. In the IR spectrum of the EA-loaded nanogels the signal around $3400 \mathrm{~cm}^{-1}$ became very broad, which is due to the phenolic hydroxyl stretch of the EA. All other bands of EA (around 1397, 1337 , and $1448 \mathrm{~cm}^{-1}$ ) and nanogels (around 3400, 2880, and $1645 \mathrm{~cm}^{-1}$ ) were observed in the spectrum of EA-loaded nanogels, particularly the presence of two characteristic peaks of EA (in the range $1300-1050 \mathrm{~cm}^{-1}$ ) in spectrum of EA-loaded nanogels confirms the absence of any chemical interaction between gel components and EA in agreement with earlier published results [12]. Therefore, EA had been encapsulated into the nanogels and had no chemical interaction with the polymeric matrix of the nanogels.

DPPH radical scavenging activity has been used earlier for the antioxidant activity evaluation of the electrospun gallic acid-loaded poly (L-lactic acid) fiber mats [29] and in vitro antioxidant activity of a peptide isolated from Nile tilapia [40], where the antioxidant activity was evaluated in a concentration dependent manner from absorbance decay at $517 \mathrm{~nm}$ and decrease in EPR signal intensity as DPPH radical got scavenged. We carried out DPPH radical scavenging activity of the EA-loaded nanogels by the absorbance decay method at $517 \mathrm{~nm}$ (Figure 6). We also recorded EPR spectra where the height of the signal reduced when the radical got scavenged. The signal height was measured at various dilutions of $1 \mathrm{mg}$ of $4.7 \mathrm{wt} . \%$ EA-loaded nanogels, that is, $1 / 10,1 / 50,1 / 100,1 / 150$. DPPH radical gives a purple colour absorbance maximum at $517 \mathrm{~nm}$, but when the radical is scavenged its absorbance decays at $517 \mathrm{~nm}$ with decrease in the intensity of the signal in EPR spectra, which gives indirectly the radical scavenging capability of the preparation (Figure 7). EA retained its radical scavenging ability even after encapsulation into the nanogels as evident from 


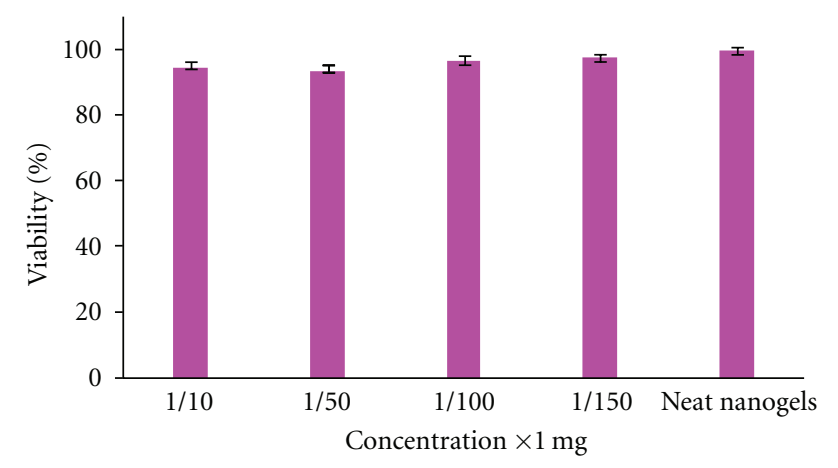

FIgUre 8: Cytotoxic effect of EA-loaded nanogels on viability of HeLa cells. Results are means \pm standard error of three independent experiments.

the concentration dependent decay of absorbance at $517 \mathrm{~nm}$ (Figure 6) as well as increase in height of the EPR signal with dilution of the formulation (Figure 7).

For any compound or delivery carrier to be proposed as a therapeutic agent, it is very important to account for their viability levels. We performed cell viability assay of the EAloaded nanogels using MTT assay on human cervical cancer cells (HeLa cells). MTT assay was performed at same dilutions those used in studying DPPH radical scavenging activity, that is, $1 / 10,1 / 50,1 / 100,1 / 150$ dilutions of the $1 \mathrm{mg}$ of $4.7 \mathrm{wt} . \%$ of the EA-loaded nanogels with $10 \mathrm{mg} / \mathrm{mL}$ concentration of the neat nanogels as control. The cell viability data (Figure 8) showed that the EA-loaded nanogels were noncytotoxic on HeLa cells.

\section{Conclusion}

Nanoparticles are being consistently used for the delivery of poorly water soluble drugs. The aims for nanoparticle entrapment of drugs are enhanced delivery to or uptake by target cells and/or a reduction in the toxicity of the free drug to nontarget organs. We have been able to develop biodegradable EA-loaded nanogels. The results indicate that the method is effective for the encapsulation of EA and it still retains its radical scavenging ability as demonstrated by DPPH assay. The encapsulation of the ellagic acid was found to be accompanied with increase in the size of nanogels, and the encapsulation efficiency was quite good if we consider the poor solubility of the EA. The combination was found to be biocompatible on HeLa cells at the concentrations used for radical scavenging activity.

\section{Conflict of Interests}

The authors declared that there is no conflict of interests.

\section{Acknowledgments}

The authors gratefully acknowledge University Grants Commission, New Delhi, India, for providing the financial assistance (Grant no. 33-279/2007 SR).

\section{References}

[1] S. U. Mertens-Talcott, S. T. Talcott, and S. S. Percival, "Low concentrations of quercetin and ellagic acid synergistically influence proliferation, cytotoxicity and apoptosis in MOLT-4 human leukemia cells," Journal of Nutrition, vol. 133, no. 8, pp. 2669-2674, 2003.

[2] S. Kim, Y. Liu, M. W. Gaber, J. D. Bumgardner, W. O. Haggard, and Y. Yang, "Development of chitosan-ellagic acid films as a local drug delivery system to induce apoptotic death of human melanoma cells," Journal of Biomedical Materials Research Part B, vol. 90, no. 1, pp. 145-155, 2009.

[3] J. N. Losso, R. R. Bansode, A. Trappey, H. A. Bawadi, and R. Truax, "In vitro anti-proliferative activities of ellagic acid," Journal of Nutritional Biochemistry, vol. 15, no. 11, pp. 672678, 2004.

[4] B. A. Narayanan, O. Geoffroy, M. C. Willingham, G. G. Re, and D. W. Nixon, "p53/p21(WAF1/CIP1) expression and its possible role in G1 arrest and apoptosis in ellagic acid treated cancer cells," Cancer Letters, vol. 136, no. 2, pp. 215-221, 1999.

[5] A. C. Whitley, G. D. Stoner, M. V. Darby, and T. Walle, "Intestinal epithelial cell accumulation of the cancer preventive polyphenol ellagic acid-extensive binding to protein and DNA," Biochemical Pharmacology, vol. 66, no. 6, pp. 907-915, 2003.

[6] L. Labrecque, S. Lamy, A. Chapus et al., "Combined inhibition of PDGF and VEGF receptors by ellagic acid, a dietary-derived phenolic compound," Carcinogenesis, vol. 26, no. 4, pp. 821826, 2005.

[7] I. Bala, V. Bhardwaj, S. Hariharan, J. Sitterberg, U. Bakowsky, and M. N. V. Ravi Kumar, "Design of biodegradable nanoparticles: a novel approach to encapsulating poorly soluble phytochemical ellagic acid," Nanotechnology, vol. 16, no. 12, pp. 2819-2822, 2005.

[8] V. Murugan, K. Mukherjee, K. Maiti, and P. K. Mukherjee, "Enhanced oral bioavailability and antioxidant profile of ellagic acid by phospholipids," Journal of Agricultural and Food Chemistry, vol. 57, no. 11, pp. 4559-4565, 2009.

[9] I. Bala, V. Bhardwaj, S. Hariharan, and M. N. V. R. Kumar, "Analytical methods for assay of ellagic acid and its solubility studies," Journal of Pharmaceutical and Biomedical Analysis, vol. 40, no. 1, pp. 206-210, 2006.

[10] R. C. Smart, M. T. Huang, R. L. Chang, J. M. Sayer, D. M. Jerina, and A. H. Conney, "Disposition of the naturally occurring antimutagenic plant phenol, ellagic acid, and its synthetic derivatives, 3-o-decylellagic acid and 3, 3'-di-o-methylellagic acid in mice," Carcinogenesis, vol. 7, no. 10, pp. 1663-1667, 1986.

[11] F. Lei, D. M. Xing, L. Xiang et al., "Pharmacokinetic study of ellagic acid in rat after oral administration of pomegranate leaf extract," Journal of Chromatography B, vol. 796, no. 1, pp. 189194, 2003.

[12] G. Sharma, J. L. Italia, K. Sonaje, K. Tikoo, and M. N. V. Ravi Kumar, "Biodegradable in situ gelling system for subcutaneous administration of ellagic acid and ellagic acid loaded nanoparticles: evaluation of their antioxidant potential against cyclosporine induced nephrotoxicity in rats," Journal of Controlled Release, vol. 118, no. 1, pp. 27-37, 2007.

[13] M. Bagul, S. Kakumanu, T. Wilson, and R. Nicolosi, "In vitro evaluation of antiproliferative effects of self-assembling nanoemulsion of paclitaxel on various cancer cell lines," Nano Biomedicine and Engineering, vol. 2, pp. 100-108, 2010.

[14] H. Song, X. Cao, J. Ruan et al., "Application of rotatable central composite design in the preparation and optimization of poly 
(lactic-co-glycolic acid) nanoparticles for controlled delivery of HSA," Nano Biomedicine and Engineering, vol. 3, pp. 34-41, 2011.

[15] W. H. De Jong and P. J. A. Borm, "Drug delivery and nanoparticles: applications and hazards," International Journal of Nanomedicine, vol. 3, no. 2, pp. 133-149, 2008.

[16] J. K. Oh, C. Tang, H. Gao, N. V. Tsarevsky, and K. Matyjaszewski, "Inverse miniemulsion ATRP: a new method for synthesis and functionalization of well-defined watersoluble/cross-linked polymeric particles," Journal of the American Chemical Society, vol. 128, no. 16, pp. 5578-5584, 2006.

[17] J. K. Oh, D. J. Siegwart, H. I. Lee et al., "Biodegradable nanogels prepared by atom transfer radical polymerization as potential drug delivery carriers: synthesis, biodegradation, in vitro release, and bioconjugation," Journal of the American Chemical Society, vol. 129, no. 18, pp. 5939-5945, 2007.

[18] J. K. Oh, D. J. Siegwart, and K. Matyjaszewski, "Synthesis and biodegradation of nanogels as delivery carriers for carbohydrate drugs," Biomacromolecules, vol. 8, no. 11, pp. 3326-3331, 2007.

[19] X. Jiang, M. C. Lok, and W. E. Hennink, "Degradablebrushed pHEMA-pDMAEMA synthesized via ATRP and click chemistry for gene delivery," Bioconjugate Chemistry, vol. 18, no. 6, pp. 2077-2084, 2007.

[20] J. A. Johnson, D. R. Lewis, D. D. Díaz, M. G. Finn, J. T. Koberstein, and N. J. Turro, "Synthesis of degradable model networks via ATRP and click chemistry," Journal of the American Chemical Society, vol. 128, no. 20, pp. 6564-6565, 2006.

[21] K. L. Heredia, Z. P. Tolstyka, and H. D. Maynard, "Aminooxy end-functionalized polymers synthesized by ATRP for chemoselective conjugation to proteins," Macromolecules, vol. 40, no. 14, pp. 4772-4779, 2007.

[22] P. L. Golas and K. Matyjaszewski, "Click chemistry and ATRP: a beneficial union for the preparation of functional materials," QSAR and Combinatorial Science, vol. 26, no. 11-12, pp. 11161134, 2007.

[23] D. J. Siegwart, J. K. Oh, H. Gao et al., "Biotin-, pyrene-, and GRGDS-functionalized polymers and nanogels via ATRP and end group modification," Macromolecular Chemistry and Physics, vol. 209, no. 21, pp. 2179-2193, 2008.

[24] D. J. Siegwart, A. Srinivasan, S. A. Bencherif et al., "Cellular uptake of functional nanogels prepared by inverse miniemulsion ATRP with encapsulated proteins, carbohydrates, and gold nanoparticles," Biomacromolecules, vol. 10, no. 8, pp. 2300-2309, 2009.

[25] M. M. Ali and H. D. H. Stöver, "Well-defined amphiphilic thermosensitive copolymers based on poly(ethylene glycol monomethacrylate) and methyl methacrylate prepared by atom transfer radical polymerization," Macromolecules, vol. 37, no. 14, pp. 5219-5227, 2004.

[26] F. Alexis, E. Pridgen, L. K. Molnar, and O. C. Farokhzad, "Factors affecting the clearance and biodistribution of polymeric nanoparticles," Molecular Pharmaceutics, vol. 5, no. 4, pp. 505515, 2008.

[27] R. Gref, A. Domb, P. Quellec et al., "The controlled intravenous delivery of drugs using PEG-coated sterically stabilized nanospheres," Advanced Drug Delivery Reviews, vol. 16, no. 23, pp. 215-233, 1995.

[28] Z. Tyeklár, R. R. Jacobson, N. Wei, N. N. Murthy, J. Zubieta, and K. D. Karlin, "Reversible reaction of $\mathrm{O}_{2}$ (and CO) with a copper(I) complex. X-ray structures of relevant mononuclear $\mathrm{Cu}(\mathrm{I})$ precursor adducts and the trans-( $\mu$-1,2-peroxo) dicopper(II) product," Journal of the American Chemical Society, vol. 115, no. 7, pp. 2677-2689, 1993.
[29] P. Chuysinuan, N. Chimnoi, S. Techasakul, and P. Supaphol, "Gallic acid-loaded electrospun poly(L-lactic acid) fiber mats and their release characteristic," Macromolecular Chemistry and Physics, vol. 210, no. 10, pp. 814-822, 2009.

[30] F. Nanjo, K. Goto, R. Seto, M. Suzuki, M. Sakai, and Y. Hara, "Scavenging effects of tea catechins and their derivatives on 1,1- diphenyl-2-picrylhydrazyl radical," Free Radical Biology and Medicine, vol. 21, no. 6, pp. 895-902, 1996.

[31] M. B. Hansen, S. E. Nielsen, and K. Berg, "Re-examination and further development of a precise and rapid dye method for measuring cell growth/cell kill," Journal of Immunological Methods, vol. 119, no. 2, pp. 203-210, 1989.

[32] N. V. Tsarevsky and K. Matyjaszewski, "Combining atom transfer radical polymerization and disulfide/thiol redox chemistry: a route to well-defined (bio)degradable polymeric materials," Macromolecules, vol. 38, no. 8, pp. 3087-3092, 2005.

[33] J. K. Oh, R. Drumright, D. J. Siegwart, and K. Matyjaszewski, "The development of microgels/nanogels for drug delivery applications," Progress in Polymer Science, vol. 33, no. 4, pp. 448-477, 2008.

[34] J. K. Oh and K. Matyjaszewski, "Synthesis of poly(2-hydroxyethyl methacrylate) in protic media through atom transfer radical polymerization using activators generated by electron transfer," Journal of Polymer Science Part A, vol. 44, no. 12, pp. 3787-3796, 2006.

[35] H. A. Aliyar, P. D. Hamilton, and N. Ravi, "Refilling of ocular lens capsule with copolymeric hydrogel containing reversible disulfide," Biomacromolecules, vol. 6, no. 1, pp. 204-211, 2005.

[36] S. Carelli, A. Ceriotti, A. Cabibbo, G. Fassina, M. Ruvo, and R. Sitia, "Cysteine and glutathione secretion in response to protein disulfide bond formation in the ER," Science, vol. 277, no. 5332, pp. 1681-1684, 1997.

[37] M. L. Hans and A. M. Lowman, "Biodegradable nanoparticles for drug delivery and targeting," Current Opinion in Solid State and Materials Science, vol. 6, no. 4, pp. 319-327, 2002.

[38] B. Chauhan, S. Shimpi, and A. Paradkar, "Preparation and characterization of etoricoxib solid dispersions using lipid carriers by spray drying technique," AAPS PharmSciTech, vol. 6, no. 3, pp. E405-E412, 2005.

[39] P. Piyakulawat, N. Praphairaksit, N. Chantarasiri, and N. Muangsin, "Preparation and evaluation of chitosan/carrageenan beads for controlled release of sodium Diclofenac," AAPS PharmSciTech, vol. 8, no. 4, pp. E1-E11, 2007.

[40] D.-H. Ngo, Z.-J. Qian, B. Ryu, J. W. Park, and S.-K. Kim, "In vitro antioxidant activity of a peptide isolated from Nile tilapia (Oreochromis niloticus) scale gelatin in free radical-mediated oxidative systems," Journal of Functional Foods, vol. 2, no. 2, pp. 107-117, 2010. 

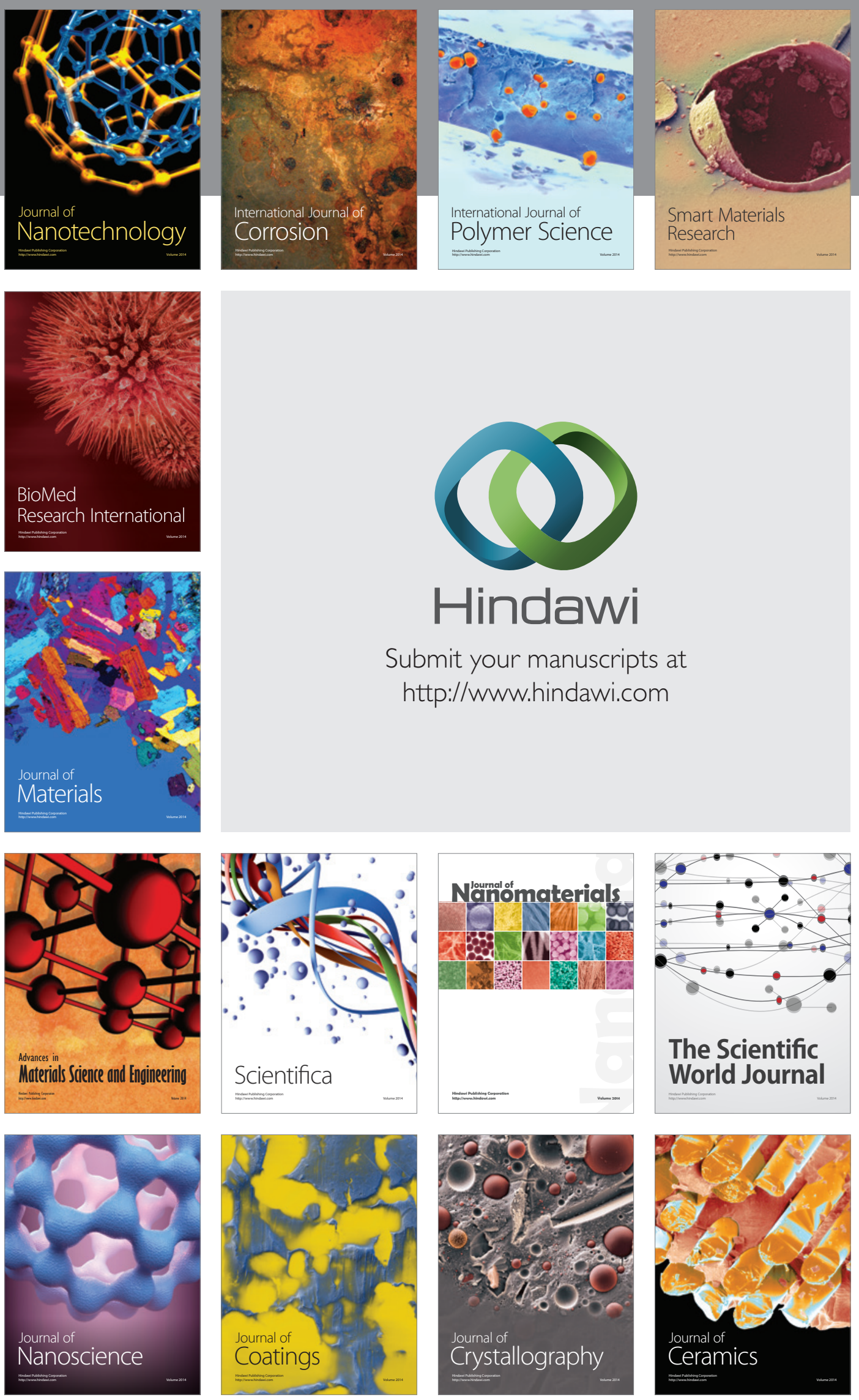

The Scientific World Journal

Submit your manuscripts at

http://www.hindawi.com

\section{World Journal}

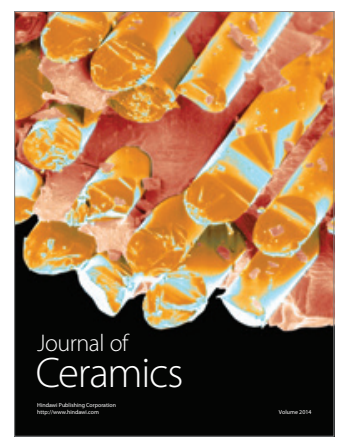

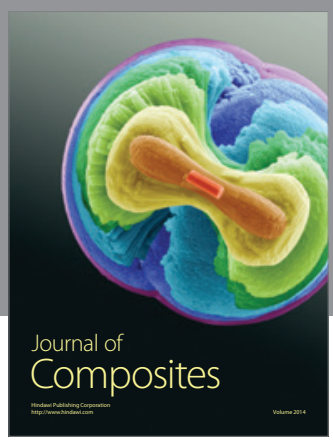
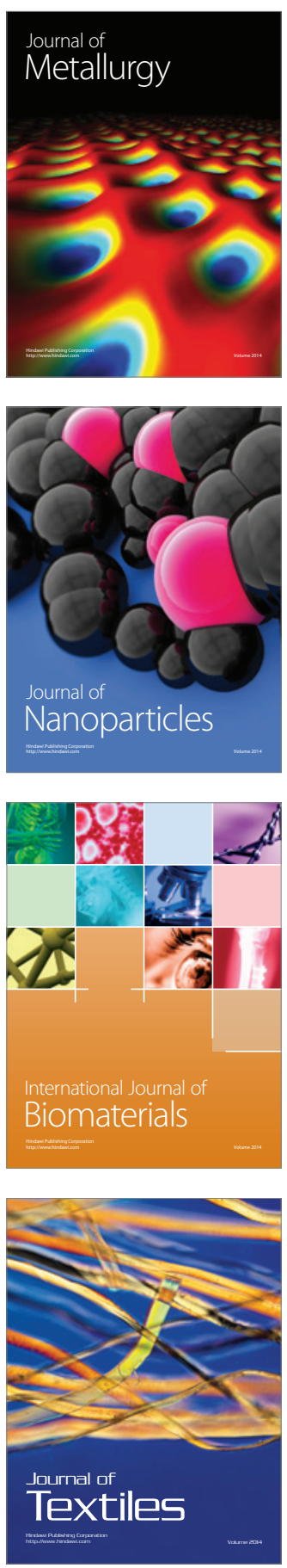